\title{
The hybrid algorithm in treatment of coronary chronic total occlusions - MSWiA Lublin CTO 5-year registry
}

\author{
Jakub Drozd, Marcin Kowalski, Tomasz Wołyniak, Monika Zaręba-Giezek \\ Department of Cardiology, SP ZOZ MSWiA, Lublin, Poland
}

Adv Interv Cardiol 2020; 16, 3 (61): 269-277

DOI: https://doi.org/10.5114/aic.2020.99261

\begin{abstract}
A bstract
Introduction: Treatment of chronic total occlusions (CTO) despite improvement in techniques and results over the last years still seems to be limited to a small number of centres and operators. Application of the hybrid strategy may support further spread of СTO percutaneous coronary intervention $(\mathrm{PCI})$ and increase procedural success rates.

Aim: Our single-centre prospective ongoing registry aims to provide details and results of recanalizations of coronary CTO performed according to the hybrid algorithm in a series of consecutive patients.

Material and methods: Between January 2015 and September 2019 the clinical and procedural data of CTO PCI procedures on consecutive patients were collected. Lesion complexity was assessed according to the Multicenter CTO Registry of Japan (J-CTO) score: 0 - easy, 1 - intermediate, 2 - difficult, $\geq 3$ - very difficult and PROGRESS score. Strategies applied were classified as: antegrade wire escalation (AWE), antegrade dissection and re-entry (ADR), retrograde wire escalation (RWE) and retrograde dissection and re-entry (RDR). Angiographic success was defined as $<30 \%$ residual stenosis with TIMI 3 flow. Angiographic and clinical complications were reported.

Results: Two hundred sixty-six patients were included and 285 procedures were performed in total. Success rate was $87.7 \%$ (calculated per procedure) and $92.5 \%$ (calculated per patient). Four patients underwent successful staged double CTO recanalization. Fifteen patients out of 31 primary failures underwent a second attempt with a $73 \%$ success rate (11/15). Fifty-two patients (18.2\%) were referred for a second attempt from other institutions. Mean J-CTO score was 2.6 (13 cases with J-CTO of 0, 41 cases with J-CTO of 1, 80 cases with J-CTO of 2 , and 151 cases with J-CTO $\geq 3$ ) and the success rate was respectively $92.3 \%, 95.1 \%, 91.3 \%$ and $83.4 \%$. Higher complexity of occlusion required a higher number of applied strategies including retrograde access in over a quarter of cases. Complete revascularization was achieved in 215 (75.4\%) cases. In-hospital MACCE rate was 3.5\% - 1 patient died due to acute kidney injury complications, 9 (3.2\%) patients sustained myocardial infarction (1 STEMI due to side branch occlusion). All 7 (2.5\%) coronary perforations (Ellis 1 and Ellis 2) were treated conservatively and we recognised 10 (3.5\%) cases of acute kidney injury (one dialysis).
\end{abstract}

Conclusions: The hybrid algorithm in CTO PCI can be successfully applied with good early results and low complication rates. Higher complexity CTOs require more procedural strategies with a significantly lower success rate in very difficult cases.

Key words: coronary chronic total occlusion, hybrid algorithm.

S u m m a ry

The purpose of the study is to present the results of the prospective single centre registry on chronic total occlusions (CTO) percutaneous coronary intervention ( $\mathrm{PCl}$ ) performed according to the hybrid algorithm. Clinical, angiographic and procedural data of $285 \mathrm{CTO} \mathrm{PCI}$ on 266 consecutive patients were collected. We report the success rate of $87.7 \%$ with a major adverse cardiovascular events rate of $3.5 \%$. The hybrid algorithm in CTO PCI proved to be an effective and safe strategy.

\section{Introduction}

Coronary chronic total occlusion (CTO) is observed in 20-30\% of patients referred for cardiac catheterisation and up to $50 \%$ of patients after previous CABG [1-3]. Despite the great progress made over the last years, including development of the new dedicated devices and grow-

\section{Corresponding author:}

Jakub Drozd MD, PhD, Department of Cardiology, SP ZOZ MSWiA, 3 Grenadierow St, 20-331 Lublin, Poland, phone: +48 817284203 ,

e-mail: jakubdrozd@poczta.onet.pl

Received: 1.04.2020, accepted: 27.06.2020. 
ing expertise in CTO percutaneous coronary interventions $(\mathrm{PCl})$, the number of operators and centres performing this kind of procedure is still limited [4-12]. Percutaneous opening of CTO is still regarded as one of the most challenging procedures in interventional cardiology. CTO remains the coronary lesion in which angioplasty is most likely to fail compared to other lesion subsets, with an average success rate around $60-70 \%$ in general and $90 \%$ in centres with dedicated CTO programmes [12-16]. On the other hand, the higher costs of equipment and the higher rate of complications discourage potential new operators. The hybrid algorithm developed by Brilakis et al. in 2012 [17] was created in order to standardise and simplify CTO PCI. Also, such an approach was found to be teachable and reproducible and laid basis for the development of other CTO dedicated algorithms including Asia Pacific CTO Club [18], CTO China Club [19], EuroCTO Club [20], and Japan CTO registry [21].

There are very few publications regarding the results of CTO PCl in Poland [22-24]. We want to present our experience in CTO treatment since adoption of the hybrid algorithm and creating a CTO programme in our institution.

\section{Aim}

Our single centre ongoing registry aims to provide details and results of coronary CTO PCI performed according to the hybrid algorithm in a series of consecutive patients.

\section{Material and methods}

We present the results of the ongoing prospective single centre registry. The current study population included all consecutive patients admitted to our institution between January 2015 and September 2019 for coronary chronic total occlusion $\mathrm{PCl}$. All procedures were performed by a single CTO operator, usually supported by a fellow interventional cardiologist.

Patients were selected for the procedure according to the general medical indications. Significant clinical symptoms of ischaemia, despite optimal medical therapy, as well as myocardial viability, were required. The myocardial viability was confirmed by preserved contractility in resting echocardiography or positive echocardiographic stress-test results, or cardiac magnetic resonance imaging (MRI) results in a few cases. The majority of the patients were treated electively except a few cases of acute coronary syndromes, when target vessel revascularization was dismissed according to angiography results (mostly failing venous grafts).

Operators applied the hybrid CTO algorithm as the basic guide for planning the strategy. The algorithm relies on careful coronary angiography assessment, mostly requiring dual catheter injections, and takes into account four major factors: the proximal cap ambiguity, appearance of the distal landing zone, presence of the interventional collaterals and the CTO lesion length. After the angiography assessment the procedure was planned, that is the first strategy was chosen according to the algorithm, as well as bailout strategies, if possible. Four strategies were considered: antegrade wire escalation (AWE), antegrade dissection and re-entry (ADR), retrograde wire escalation (RWE) and retrograde dissection and re-entry (RDR). AWE was the strategy of choice in the case of a clear proximal cap, good landing zone and lesion length less then $20 \mathrm{~mm}$. In the case of a longer lesion ADR techniques were applied, either catheter based (CrossBoss/Stingray system) or wire based including subintimal tracking and re-entry (STAR and miniSTAR) and limited integrate subintimal tracking (LAST). In the case of proximal cap ambiguity or poor distal target and the presence of good "interventional collaterals" retrograde strategies were chosen, i.e. RWE with direct lumen-to-lumen wire crossing in the case of short occlusion or in longer lesion retrograde dissection re-entry (RDR), i.e. reverse controlled antegrade and retrograde tracking ( $\mathrm{rCART}$ ) in most cases.

CTO was defined as the native coronary artery occlusion lasting more than 3 months with antegrade TIMI 0 flow [20]. Proximal cap ambiguity was defined as the inability to decide the exact point of occlusion. Lesion length was estimated on the basis of balloon, stent or radiopaque distal wire marker length during dual catheter angiography. A poor distal landing zone was defined as one with significant stenosis, presence of an important side branch or of size less than $2 \mathrm{~mm}$. "Interventional collaterals" were those suitable for retrograde crossing according to the operator's experience.

Complexity of the occlusion was graded according to J-CTO [25] and PROGRESS [26] scores. In brief, J-CTO score takes into account five factors: tapering of the proximal cap, presence of coronary calcifications, bending more than $45^{\circ}$ in occluded segment, occlusion length more than $20 \mathrm{~mm}$ and prior failed attempt. The difficulty of CTO crossing was categorised as: simple (0 point), intermediate (1 point), difficult ( 2 points) and very difficult (3 or more points). PROGRESS score was calculated according to presence of four factors: proximal cap ambiguity, absence of interventional collaterals, tortuosity within occluded segment ( 2 bends more than $70^{\circ}$ or one bend more than $90^{\circ}$ ) and CX CTO.

All the major demographic and clinical data were collected. Procedure time, fluoroscopy time, dose exposure, dose area product (DAP) and contrast volume were calculated. Serum high sensitivity troponin I (hsTnl), CKMB and creatinine were routinely collected prior to the procedure and within 48-72 $\mathrm{h}$ after $\mathrm{PCl}$. Hospital major adverse coronary and cerebrovascular events (MACCE) were reported: death, myocardial infarction according to Third Universal Definition [27], changed into Fourth Universal Definition in 2018 [28], and stroke. Bleeding complications according to BARC criteria were assessed [29]. Coronary vascu- 
lar complications included: perforation (according to Ellis classification) [30], donor artery dissection or thrombosis and in-hospital target vessel revascularization. Other major vascular complications included: aortic dissection and puncture site complications leading to additional interventions or severe consequences (for example: limb ischaemia, neurological impairment). We also reported incidents of contrast induced nephropathy (CIN), defined as either $25 \%$ increase in serum creatinine ( $\mathrm{SCr}$ ) from baseline or $0.5 \mathrm{mg} / \mathrm{dl}$ increase in absolute $\mathrm{SCr}$ value.

Procedural success was defined as artery opening with less than $30 \%$ residual stenosis within occluded segment and TIMI 3 flow.

All patients gave their written informed consent. The study was approved by the regional ethics committee.

\section{Statistical analysis}

Continuous variables were presented as mean \pm SD . Categorical variables were expressed as absolute numbers and percentages. Normality was assessed with the Kolmogorov-Smirnov test. Pearson's $\chi^{2}$ test was applied to evaluate the association between qualitative variables. Student's $t$-test was used to compare normally distributed variables and the Mann-Whitney $U$ or Kruskal-Wallis test for abnormally distributed continuous variables among groups. All statistical analyses were carried out using Statistica 13.3 (StatSoft, USA).

\section{Results}

A total of 285 CTO PCI procedures was performed in 266 patients (Figure 1). In 4 patients double CTO was performed on separate occasions. Fifteen reattempts were made and their CTO characteristics were taken from the first procedure. The success rate calculated per procedure was $87.7 \%(250 / 285)$ and per patient was $92.5 \%$ $(246 / 266)$.
The demographics of the patients are shown in Table I. Three quarters (75.5\%) of the patients were male, with significantly lower percentage of males amongst failed cases (57.1\%). Mean age was $66 \pm 10$ years, $29.5 \%$ had diabetes, $54.7 \%$ prior myocardial infarction (MI), $69.8 \%$ prior $\mathrm{PCl}$ and $10.9 \%$ prior coronary artery bypass grafting (CABG).

The commonest indication for $\mathrm{PCl}$ was stable angina $(92,2 \%)$, with a few cases of unstable angina (2.5\%), non-ST-elevation myocardial infarction (NSTEMI) (1.8\%), high risk ventricular arrhythmia (1.8\%) and congestive heart failure $(1,8 \%)$. Most of the patients $(69.1 \%)$ had preserved left ventricular ejection fraction of more than $50 \%$.

The right coronary artery was the site of СTO in $59.6 \%$ of the cases, left anterior descending in $25.2 \%$, circumflex in $14.4 \%$, left main in $1(0.4 \%)$ case as well as diagonal branch (0.4\%) (Table II). The proportion of single, double and triple vessel disease was respectively: $41 \%, 36.5 \%$ and $22.5 \%$. Majority (95.3\%) of the CTO lesions were "de novo". Fifty-two (18.2\%) procedures were second attempts referred from other institutions. The percentage of referred patients was significantly higher in the failure group, $28.6 \%(10 / 35)$ vs. $16.8 \%(42 / 250)$ $(p<0.05)$. Mean J-CTO score was $2.6 \pm 1.2$. It was $2.5 \pm 1.2$ in the successful and $2.9 \pm 1.2$ in the failed group (NS). Mean PROGRESS score was $0.9 \pm 0.9$. It was $0.8 \pm 0.9$ in the successful and $1.2 \pm 0.9$ in the failed group (NS). In 160 (56.1\%) cases CTO PCI was a single procedure, in 125 (43.9\%) cases it was part of the staged revascularization, including 4 cases of double CTO PCI. Fifteen patients underwent a second attempt procedure out of which 11 were successful (73.3\%). Mean Syntax score was 19.5 \pm 12 .2, equal in successful $(20 \pm 12.2)$ and in failed groups (15.6 \pm 11.6$)$, and improved to rSYNTAX score $2.5 \pm 6.5$, respectively: $1 \pm 3.7$ vs. $14.3 \pm 10.4$. Complete revascularization was achieved in $75.4 \%$ of total, and in $86 \%$ of successful cases.

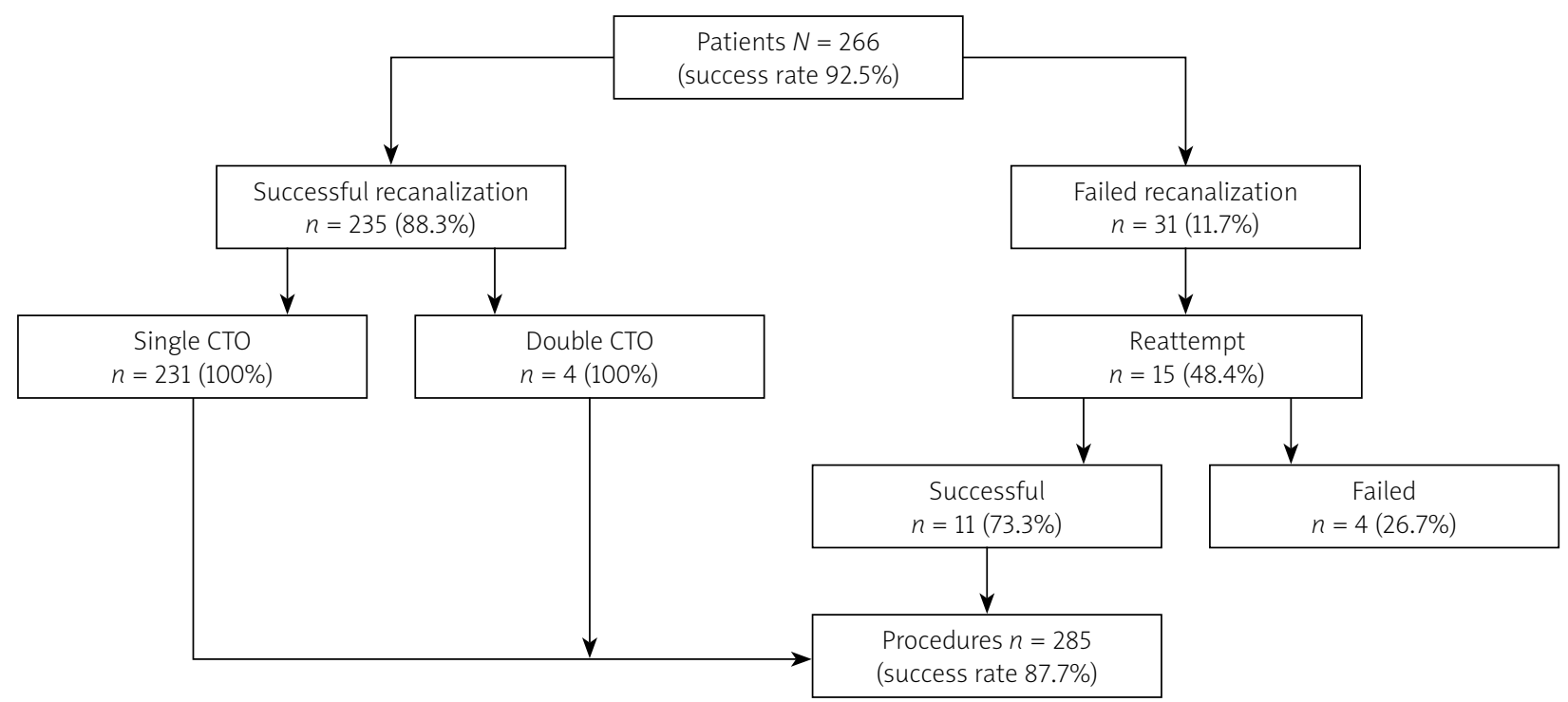

Figure 1. Procedural flow chart 
Table I. Demographic characteristics

\begin{tabular}{|c|c|c|c|c|}
\hline Parameter & $\begin{array}{c}\text { All } \\
N=285(\%) \\
\end{array}$ & $\begin{array}{c}\text { Successful } \\
n=250(\%)\end{array}$ & $\begin{array}{c}\text { Failed } \\
n=35(\%)\end{array}$ & $P$-value \\
\hline Age & $66 \pm 10(37-88)$ & $65 \pm 10(37-84)$ & $67 \pm 10(41-88)$ & NS \\
\hline Male & $215(75.5)$ & $195(78.1)$ & $20(57.1)$ & 0.01 \\
\hline Hypertension & $234(82.1)$ & $207(82.8)$ & $27(77.1)$ & NS \\
\hline Smoking & $190(66.7)$ & $173(69.2)$ & 17 (48.6) & NS \\
\hline Diabetes & $84(29.5)$ & 74 (29.6) & $10(28.6)$ & NS \\
\hline Hyperlipidaemia & $192(67.3)$ & $171(68.4)$ & $21(60)$ & NS \\
\hline PVD & $63(22.1)$ & $53(21.2)$ & $10(28.6)$ & NS \\
\hline CKD & $112(39.3)$ & $87(38.8)$ & 15 (42.9) & NS \\
\hline Previous $\mathrm{PCl}$ & $199(69.8)$ & $177(70.8)$ & $22(62.9)$ & NS \\
\hline Previous CABG & 31 (10.9) & 27 (10.8) & $4(11.4)$ & NS \\
\hline SCAD & $263(92.2)$ & $235(94)$ & $28(80)$ & \\
\hline UA & $7(2.5)$ & $7(2.8)$ & $0(0)$ & \\
\hline NSTEMI & $5(1.8)$ & $1(0.4)$ & $4(11.4)$ & NS \\
\hline Arrhythmia & $5(1.8)$ & $5(2.0)$ & $0(0)$ & \\
\hline $\mathrm{CHF}$ & $5(1.8)$ & $2(0.8)$ & $3(8.6)$ & \\
\hline \multicolumn{5}{|l|}{ EF: } \\
\hline$>50 \%$ & $197(69.1)$ & $177(70.8)$ & $20(57.1)$ & \\
\hline $35-50 \%$ & 53 (18.6) & 46 (18.4) & $7(20.0)$ & NS \\
\hline$<35 \%$ & $15(5.4)$ & $7(2.8)$ & $8(22.8)$ & \\
\hline NA & $20(7.0)$ & $20(9.0)$ & $0(0)$ & \\
\hline
\end{tabular}

Table II. Angiographic characteristics

\begin{tabular}{|c|c|c|c|c|}
\hline Parameter & $\begin{array}{c}\text { All } \\
N=285(\%)\end{array}$ & $\begin{array}{c}\text { Successful } \\
n=250(\%)\end{array}$ & $\begin{array}{c}\text { Failed } \\
n=35(\%)\end{array}$ & $P$-value \\
\hline \multicolumn{5}{|l|}{ Artery: } \\
\hline$\overline{R C A}$ & $170(59.6)$ & $144(57.6)$ & $26(74.3)$ & \\
\hline$\overline{L A D}$ & $72(25.2)$ & $65(26)$ & $7(20)$ & \\
\hline$\overline{C x}$ & $41(14.4)$ & 39 (15.6) & $2(5.7)$ & 0.01 \\
\hline$\overline{L M}$ & $1(0.4)$ & $1(0.4)$ & $0(0)$ & \\
\hline$\overline{D I A}$ & $1(0.4)$ & $1(0.4)$ & $0(0)$ & \\
\hline \multicolumn{5}{|l|}{ N-vessel disease: } \\
\hline $1-$ & $117(41)$ & $102(40.8)$ & $15(41.7)$ & \\
\hline $2-$ & $104(36.5)$ & $93(37.2)$ & $11(30.6)$ & NS \\
\hline $3-$ & $64(22.5)$ & $55(22)$ & $9(27.7)$ & \\
\hline De novo & $273(95.3)$ & $238(95.2)$ & $35(100)$ & NS \\
\hline Second attempt & $52(18.2)$ & $42(16.8)$ & $10(28.6)$ & 0.05 \\
\hline J-СТО & $2.6 \pm 1.2(0-5)$ & $2.5 \pm 1.2$ & $2.9 \pm 1.2$ & NS \\
\hline PROGRESS SCORE & $0.9 \pm 0.9$ & $0.8 \pm 0.9$ & $1.2 \pm 0.9$ & NS \\
\hline Syntax Score & $19.5 \pm 12.2$ & $20 \pm 12.2$ & $15.6 \pm 11.6$ & NS \\
\hline rSyntax Score & $2.5 \pm 6.5$ & $1 \pm 3.7$ & $14.3 \pm 10.4$ & $<0.0000$ \\
\hline Complete revasc & $215(75.4)$ & $215(86)$ & 0 & - \\
\hline
\end{tabular}


Table III. Procedural details

\begin{tabular}{|c|c|c|c|c|}
\hline Parameter & $\begin{array}{c}\text { All } \\
N=285(\%) \\
\end{array}$ & $\begin{array}{c}\text { Successful } \\
n=250(\%)\end{array}$ & $\begin{array}{c}\text { Failed } \\
n=35(\%)\end{array}$ & $P$-value \\
\hline Procedure time [min] & $\begin{array}{l}108 \pm 43.7 \\
(16-260)\end{array}$ & $\begin{array}{c}105 \pm 42.4 \\
(16-255)\end{array}$ & $\begin{array}{l}132 \pm 45.8 \\
(50-260)\end{array}$ & $<0.001$ \\
\hline Fluoroscopy time [min] & $\begin{array}{c}46.9 \pm 25.9 \\
(6-154) \\
\end{array}$ & $\begin{array}{c}42.9 \pm 24.1 \\
(6-135) \\
\end{array}$ & $\begin{array}{c}66.1 \pm 29.3 \\
(22-154) \\
\end{array}$ & $<0.0000$ \\
\hline $\mathrm{DAP}\left[\mathrm{cGy} / \mathrm{cm}^{2}\right]$ & $\begin{array}{c}246067 \pm 148999 \\
(6926-709109)\end{array}$ & $\begin{array}{c}232462 \pm 143956 \\
(6926-709109)\end{array}$ & $\begin{array}{c}344299 \pm 151624 \\
(106885-678625)\end{array}$ & $<0.001$ \\
\hline Exposure dose [mGy] & $\begin{array}{l}2383 \pm 1400 \\
(269-7668)\end{array}$ & $\begin{array}{l}2258 \pm 1350 \\
(269-7633)\end{array}$ & $\begin{array}{c}3397 \pm 1447 \\
(1064-7668)\end{array}$ & $<0.003$ \\
\hline Contrast volume [ml] & $\begin{array}{l}222 \pm 102 \\
(65-550) \\
\end{array}$ & $\begin{array}{l}220 \pm 102 \\
(65-550) \\
\end{array}$ & $\begin{array}{c}245 \pm 99 \\
(110-460) \\
\end{array}$ & NS \\
\hline Number of stents (range) & - & $\begin{array}{c}1.82 \pm 0.79 \\
(1-4)\end{array}$ & - & - \\
\hline Stent length $[\mathrm{mm}]$ & - & $65.1 \pm 25.1(0-140)$ & - & - \\
\hline Microcatheter (range) & $\begin{array}{c}0.79 \pm 0.65 \\
(1-3)\end{array}$ & $\begin{array}{c}0.75 \pm 0.65 \\
(1-3)\end{array}$ & $\begin{array}{c}1.10 \pm 0.74 \\
(1-3)\end{array}$ & $<0.001$ \\
\hline ADR system & $0.063 \pm 0.22$ & $0.052 \pm 0.21$ & $0.14 \pm 0.34$ & $<0.001$ \\
\hline Number of wires (range) & $\begin{array}{c}4.7 \pm 2.3 \\
(1-11)\end{array}$ & $\begin{array}{c}4.5 \pm 2.3 \\
(1-11)\end{array}$ & $\begin{array}{c}5.9 \pm 2.3 \\
(1-9)\end{array}$ & 0.03 \\
\hline
\end{tabular}

Overall success rate was $87.7 \%$ calculated per procedure. Taking J-CTO score as a complexity marker success rate was $92.3 \%(12 / 13)$ in easy (J-CTO 0), 95.1\% (39/41) in intermediate (J-CTO 1), 91.3\% (73/80) in difficult (J-CTO 2) and $83.4 \%(126 / 151)$ in very difficult cases (J-CTO $\geq 3)$.

Dual catheter injections were applied in $67.4 \%$ $(192 / 285)$; in remaining cases ipsilateral visualisation was adequate. In most unilateral injection cases $(90.3 \%$, 84/93) a radial approach was applied, while in bilateral injection cases mostly combined radial-femoral access was used (92.7\%, 178/192).

Failed procedures took significantly more time, required more $\mathrm{x}$-ray exposure and contrast volume than successful ones (Table III). The average number of guidewires used per procedure was $4.7 \pm 2.3$ (higher in failed group) and microcatheters $0.7 \pm 0.6$. Stents were implanted in $97.2 \%$ of successful cases (243/250), average stent number was $1.8 \pm 0.8$ and stent length $65.1 \pm 25.1 \mathrm{~mm}$. The CrossBoss/Stingray system was applied in 18 ADR cases.

Four strategies were considered prior to each procedure: AWE, ADR, RWE, RDR. Six hundred and six options were planned in total, 540 (2.1 \pm 0.7 per procedure $)$ in eventually successful procedures and 66 (1.9 \pm 0.7 per procedure) in failed ones (NS). The number of planned single technique procedures was higher in failed cases (34\% vs. 21\%) (Figure 2), while three techniques considered as available were more common in successful cases (37\% vs. 23\%). Eventually 429 techniques were applied, $1.5 \pm 0.7$ per procedure in successful and $1.7 \pm 0.7$ in failed cases, respectively: single in $65 \%$ vs. $46 \%$, double $22 \%$ vs. $40 \%$ and triple in $13 \%$ vs. $14 \%$ cases. Single technique was used in every easy case according to J-CTO score $(13 / 13)$. More than one technique required $12.2 \%$ (5/41) in the intermediate group, 38.8\% (31/80) in the difficult group and $47.0 \%(71 / 151)$ in the very difficult group (Figure 3). Antegrade techniques were applied 288 times and retrograde 141 times. The commonest first line strategy was AWE (89.1\%, 254/285), followed by RWE (7.0\%, 20/285), ADR $(2.1 \%, 6 / 285)$ and RDR $(1.8 \%, 5 / 285)$. The second crossing strategy was applied 106 times: RWE

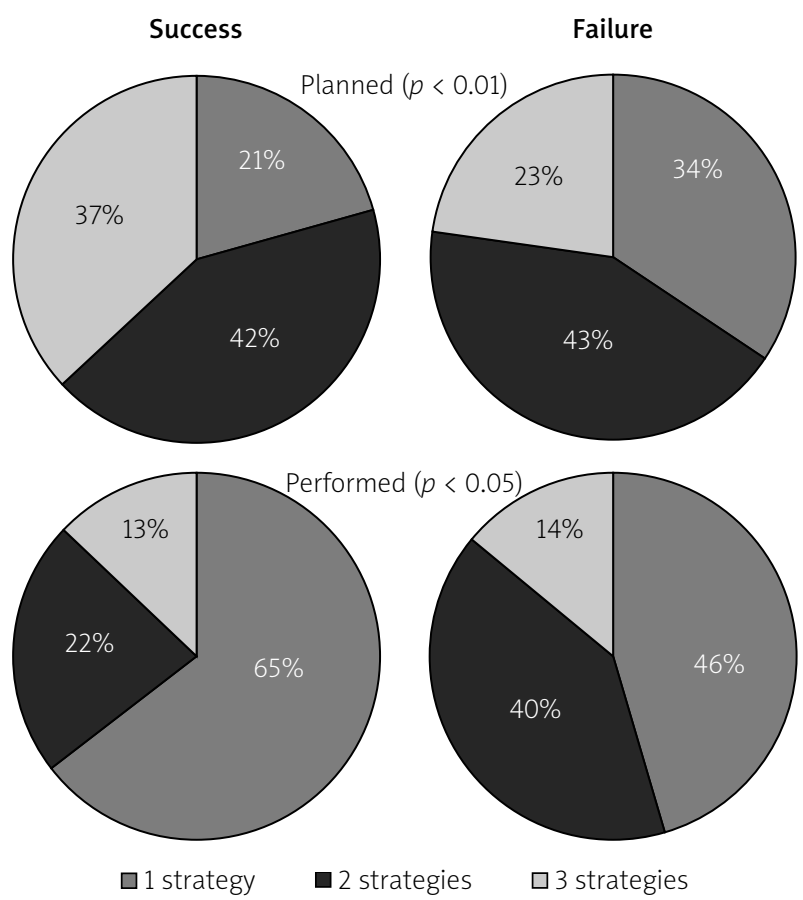

Figure 2. Number of procedural strategies planned and performed in successful and failed coronary chronic total occlusion percutaneous coronary intervention 


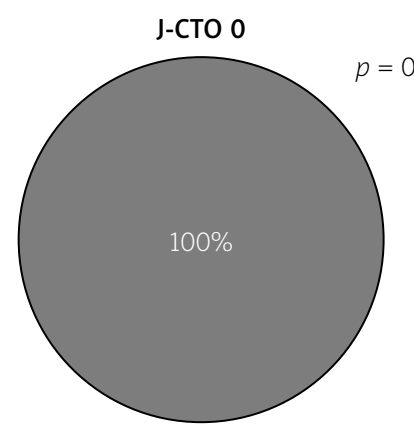

J-CTO 2

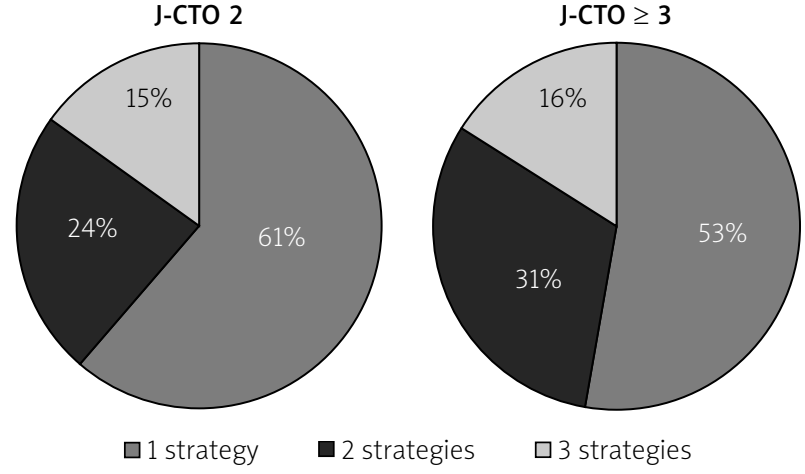

Figure 3. Number of procedural strategies applied according to J-CTO score

(55.7\%, 59/106), RDR (23.6\%, 25/106), ADR (12.3\%, 13/106) and AWE $(8.5 \%, 9 / 106)$ and the third 37 times, respectively RWE $(75.7 \%, 28 / 37)$, ADR $(16.2 \%, 6 / 37)$ and RWE $(8.1 \%, 3 / 37)$. AWE was a final successful strategy in $100 \%$ of the easy group, in $89 \%$ of the intermediate group, in $70 \%$ of the difficult group and in $48 \%$ of very difficult cases when taking into account successful cases. Success rate of applied AWE was 92.3\% (12/13) in J-CTO 0, 82.9\% (34/41) in J-CTO 1, 71.8\% (51/71) in J-CTO 2 and $47.7 \%(62 / 130)$ in J-CTO $\geq 3$ (Figure 4$)$. ADR was applied 34 times (11.9\%), device based in 18 cases (CrossBoss/Stingray in 10, CrossBoss alone in 5 and Stingray alone in 3 cases) and wire based in 16 cases (LAST in 8 , miniSTAR in 4 and STAR in 4 cases). ADR was chosen as a first strategy in 6 cases, all with J-CTO score $\geq 3$, and applied mostly in complex lesions. Total success rate of ADR was 67.6\% (23/34), wire based ADR 62.5\% (10/16) and device based ADR 72.2\% (13/18). Retrograde techniques were applied 141 times, mostly RWE $(n=89)$. The success rate of RWE was $23.6 \%$ (21/89) and if it failed it was usually followed by RDR with its final success rate of $96.1 \%(50 / 52)$. The retrograde techniques were successful in $7.3 \%$ (3/41) of J-CTO 1, 29.6\% (21/71) of J-CTO 2 and $36.2 \%(47 / 130)$ of J-CTO $\geq 3$ cases and their overall success rate was respectively 75\% (3/4), 50\% (21/42) and $49.5 \%$ (47/95). Intravascular ultrasound (IVUS) was used in $20(7 \%)$ cases and rotational atherectomy in $2(0.7 \%)$ cases.

In-hospital MACCE (Table IV) occurred in 10 (3.5\%) cases. One patient with severe renal disease (baseline
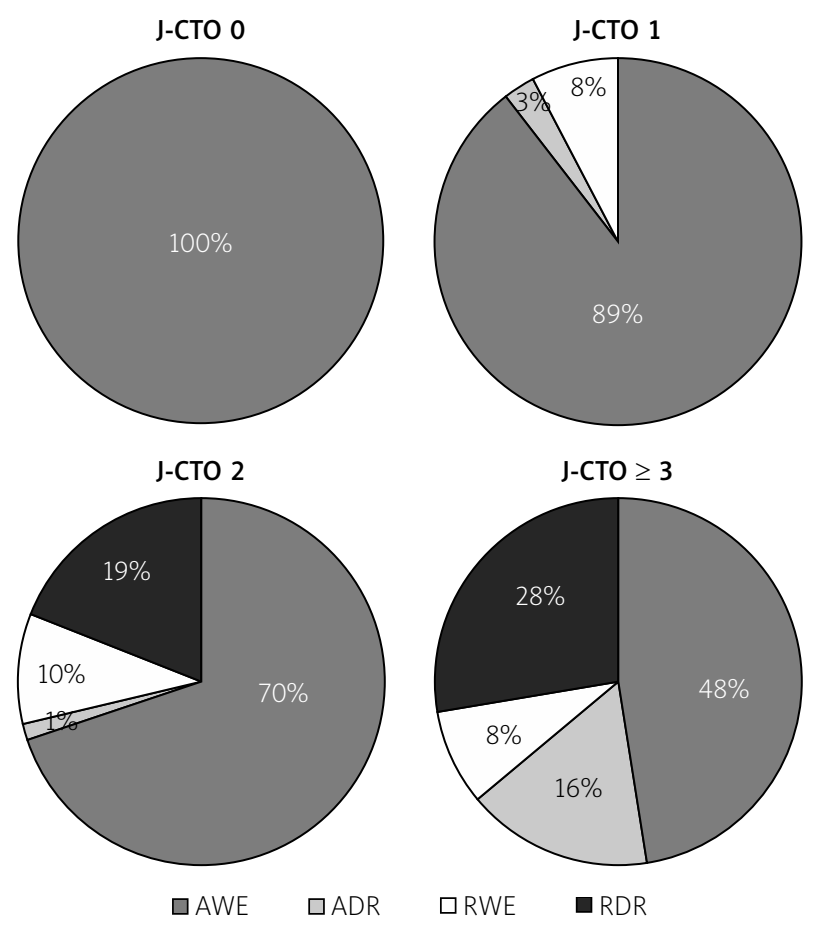

Figure 4. Successful strategy according to J-CTO score

eGFR $=27 \mathrm{ml} / \mathrm{h}$ ) died 14 days after a successful LAD CTO procedure due to the complications of haemodialysis required after renal function deterioration. Nine myocardial infarctions, including one STEMI after side branch occlusion and 8 NSTEMI, were diagnosed. Major coronary complications occurred in 10 (3.5\%) cases - they were coronary perforations, Ellis 1 and Ellis 2, all treated medically, not leading to tamponade or requiring pericardiocentesis. No major bleeding, cerebral or vascular complications were noted. Contrast induced nephropathy was diagnosed in 10 (3.5\%) cases, all treated medically except one. The complications were more frequent in the failure group, although the difference, except perforations, was not statistically significant.

\section{Discussion}

Chronic total occlusions are often described as the "final frontier" of percutaneous coronary interventions. The reason for that was traditionally lower success (60$70 \%$ ) and higher complication (3\%) rates, which eventually lead to incomplete revascularization and often referral to coronary bypass surgery (1-3.5). During the last two decades new equipment including guidewires and microcatheters as well as new crossing techniques, such as retrograde and dissection-and-re-entry, have been introduced. They significantly improved both early and long-term results, the latter especially due to DES, debulking devices, intravascular imaging and pharmacotherapy. Nevertheless, adoption of CTO PCI remains low. An explanation for that might be the false opinion that 
Table IV. In-hospital complications

\begin{tabular}{|c|c|c|c|c|}
\hline Parameter & $\begin{array}{c}\text { All } \\
N=285(\%)\end{array}$ & $\begin{array}{c}\text { Successful } \\
n=250(\%)\end{array}$ & $\begin{array}{c}\text { Failed } \\
n=35(\%)\end{array}$ & $P$-value \\
\hline MACCE: & $10(3.5)$ & $7(2.8)$ & $2(5.7)$ & NS \\
\hline Death & $1(0.4)$ & $1(0.4)$ & $0(0)$ & NS \\
\hline $\mathrm{Ml}$ & $9(3.2)$ & $8(3.2)$ & $2(5.7)$ & NS \\
\hline STEMI & $1(0.4)$ & $1(0.4)$ & 0 & NS \\
\hline NSTEMI & $8(2.8)$ & $7(3.5)$ & $2(6.7)$ & NS \\
\hline Stroke & 0 & 0 & 0 & - \\
\hline \multicolumn{5}{|l|}{ Others: } \\
\hline Perforation & $10(3.5)$ & $6(2.4)$ & $4(11.4)$ & 0.01 \\
\hline Tamponade & 0 & 0 & 0 & - \\
\hline TVF/TVR & 0 & 0 & 0 & - \\
\hline Haemorrhage & 0 & 0 & 0 & - \\
\hline Vascular & 0 & 0 & 0 & - \\
\hline CIN & $10(3.5)$ & 8 (3.3) & $2(6.7)$ & NS \\
\hline
\end{tabular}

CTO $\mathrm{PCl}$ is restricted to exceptionally gifted operators. According to EuroCTO Club previous recommendation from 2007, to become an experienced CTO operator one must perform at least 300 procedures and a minimum of 50 procedures per year to maintain competency. The idea of a CTO PCI "algorithm" was to create a platform for analysing angiography, planning the strategy and swift change in procedure flow to make it effective and safe and at the same time teachable and reproducible. The hybrid algorithm has been proved to have a high success rate in numerous studies in the United States and Europe $[11,12,14,16]$.

To the best of our knowledge this is the largest study published to date in Poland reflecting the results of contemporary CTO PCI. The registry was conducted in a centre with the operator experienced in antegrade CTO PCI whose previously reported success rate was 75\% [22] and who underwent relatively short training in ADR and retrograde interventions [24]. The registry shows that the hybrid algorithm can be adopted over a short period of time with results comparable to other studies.

Procedural success rate was $87.7 \%$, a result similar to the recently published results of the biggest registries: ERCTO - 89.3\% in 2014-2015 [15], Japanese Retrograde Summit Registry - 88.4\% [13], and two "hybrid algorithm" registries: the RECHARGE Registry conducted in Europe with $86 \%$ success rate [12] and the PROGRESS CTO Registry in USA - 87\% [16]. Like both ERCTO and National Cardiovascular Data Registry [31], which showed an increasing success rate over time from around 60-70\% in 2008 to nearly $90 \%$ in 2015, and even higher in high volume dedicated centres, we noted a sharp increase since the adoption of $A D R$ and retrograde techniques and integrating them in the hybrid algorithm. A few studies have documented an increase in success rate after implementation of the hybrid algorithm. A small study reported a success rate of $92 \%$ with $0 \%$ in-hospital mortality achieved by a single "СTO naive", but overall highly experienced operator, within 6 months and in 50 CTO cases since algorithm adoption [32]. Another study from a high volume centre [33] showed that after adoption of the hybrid algorithm, technical success was significantly higher in the post-algorithm group, 189/198 (95.4\%), vs. the pre-algorithm group, 367/462 (79.4\%).

Our study also showed a remarkably high success rate of reattempts (73.3\%), documented also in the RECHARGE registry, giving a final success rate of $92.5 \%$ calculated per patient.

The success was achieved with a 3.5\% rate of major complications, driven mainly by uncomplicated periprocedural NSTEMI, with an overall low mortality rate $(0.4 \%)$. The reported complications rate in other studies ranged from $0.5 \%$ to $3.1 \%$ and the mortality rate $0.1-0.85 \%[12,13,15,16]$. Noteworthy, not all registries reported their criteria for $\mathrm{MI}$ recognition or admit other than Third or Fourth Definition criteria used $[12,15]$. We did not observe a difference between success and failure groups, often reported in other studies $[15,16]$ but not all $[12,14]$, which might be related to our small study group.

The mean procedure time of 108 min was shorter than in OPEN CTO (120 min) and PROGRESS CTO (123 $\mathrm{min}$ ) but longer than in RECHARGE (90 min); likewise, exposure dose was 2.4 Gy, compared to 2.5 Gy, 2.9 Gy and $1.6 \mathrm{~Gy}$ and fluoroscopy time $47 \mathrm{~min}$ vs. $47 \mathrm{~min}, 50 \mathrm{~min}$, 
and $35 \mathrm{~min}$. The mean contrast volume in our registry was $222 \mathrm{ml}$ and was slightly smaller than in other registries (250-280 ml).

Our population was characterised by high lesion complexity (mean J-CTO score 2.6, PROGRESS Score 0.9), but unlike other studies (RECHARGE, PROGRESS) there was no significant difference between success and failure groups. One must remember that both scores perform modestly well for retrograde procedures [34]. We also noted some discrepancy between J-CTO and PROGRESS CTO score, which might be related to the considerable percentage of patients referred for a second attempt, the factor incorporated in J-CTO score calculation.

Antegrade wire escalation was the commonest initial crossing strategy (89.1\%), especially in lower complexity cases (J-CTO $0-100 \%$, J-CTO $1-88 \%$ ) and was the final successful strategy in nearly two thirds. A study showed that the success rate of AWE declined with the complexity increase. Retrograde techniques were used initially in nearly $10 \%$ of the cases, mostly with more complex anatomy, and were the final successful strategy in $28.4 \%$. ADR was infrequently used as a frontline strategy (2.1\%), mostly in complex lesions ( $4.6 \%$ in J-CTO $\geq 3$ ), and was the final successful strategy in $9.2 \%$ of all cases. In $59 \%$ of cases the initial crossing strategy was successful. We found that higher complexity cases required more than one crossing technique and that in a third of difficult cases and in more than half of very difficult cases retrograde or ADR techniques were applied.

In practice, the hybrid algorithm should be treated like a roadmap, and tailored to local practice and expertise. For example, high AWE percentage as a primary crossing strategy is partially related to its application as a preparation prior to retrograde technique in order to shorten in-dwelling time of retrograde equipment. Ambiguity of the proximal cap could be resolved by anterograde "scratch-and-go" or BASE techniques and IVUS. The almost invisible septal collaterals or tortuous epicardial collaterals could be seen as promising retrograde interventional conduits as well as "out-of-reach", depending on the operator's experience. Adoption of ADR was lower than in US PROGRESS (31.7\%) or European RECHARGE (23\%) registries but higher than in the EuroCTO Club (5.5\%) or Japanese registries (0\%), proving that factors other than economic constraints stand for its confined application in the two latter populations.

The hybrid algorithm is the first one which was created to optimise and simplify the decision making process in cases of CTO PCI. It is also the most documented and validated in medical literature $[12,14,16,17]$. Since its formation many other algorithms have been created, most of them taking the construct from the original one. For example the expanded hybrid algorithm [35] or The Asia Pacific Club algorithm [18]. Only recently, EuroCTO Club released its own algorithm, accommodating a reluctant approach to the ADR idea but with the concept of "the investment procedure" [20]. The newest one came from The Japanese CTO-PCI Expert Registry, and it relies on both angiographic characteristics and wire manipulation time and promotes a retrograde approach even through higher-risk collaterals, which reflects local expertise [21]. There are very sparse data on the performance of all new algorithms, although the elements of some of them are routinely appreciated and used by "hard core" hybrid algorithm operators, i.e. cap ambiguity resolution, "investment procedure" concept, subintimal plaque modification, parallel wire technique. However, there seem to exist strong local preferences in CTO PCI techniques which might preclude formation of a global universal algorithm readily adopted in different mental and economic circumstances.

This is a single operator registry and reflects the practice of a single centre. The choice of used materials and strategies might have been subjected to individual experience and preferences. We did not calculate periprocedural complications according to the applied strategy, mainly because of their small number. The procedural characteristics and outcomes were not validated by an independent core lab. The aim of our study was not to deliver data on long term follow-up.

\section{Conclusions}

The hybrid algorithm in CTO $\mathrm{PCl}$ can be successful applied with good early results and low complication rates. Higher complexity CTOs require more procedural strategies with a significantly lower success rate in very difficult cases.

\section{Conflict of interest}

J.D. has received consulting fees from Biotronik, Boston Scientific, Terumo. Other authors declare no conflict of interest.

\section{References}

1. Werner GS, Gitt AK, Zeymer U, et al. Chronic total coronary occlusions in patients with stable angina pectoris: impact on therapy and outcome in present day clinical practice. Clin Res Cardiol 2009; 98: 435-41.

2. Jeroudi OM, Alomar OM, Michael TT, et al. Prevalence and management of coronary chronic total occlusions in a tertiary Veterans Affairs hospital. Cath Cardiovasc Interv 2014; 84: 637-43.

3. Fefer P, Knudtson ML, Cheema AN, et al. Current perspectives on coronary chronic total occlusions: the Canadian Multicenter Chronic Total Occlusions Registry. J Am Coll Cardiol 2012; 59: 991-7.

4. Saito S. Different strategies of retrograde approach in coronary angioplasty for chronic total occlusion. Cath Cardiovasc Interv 2008; 71: 8-19.

5. Rathore S, Katoh O, Matsuo H, et al. Retrograde percutaneous recanalization of chronic total occlusion of the coronary arteries: procedural outcomes and predictors of success in contemporary practice. Circulation Cardiovasc Interv 2009; 2: 124-32.

6. Whitlow PL, Burke MN, Lombardi WL, et al. Use of a novel crossing and re-entry system in coronary chronic total occlusions that 
have failed standard crossing techniques: results of the FAST-CTOs (Facilitated Antegrade Steering Technique in Chronic Total Occlusions) trial. J Am Coll Cardiol Cardiovasc Interv 2012; 5: 393-401.

7. Brilakis ES, Grantham JA, Thompson CA, et al. The retrograde approach to coronary artery chronic total occlusions: a practical approach. Catheter Cardiovasc Interv 2012; 79: 3-19.

8. Michael TT, Papayannis AC, Banerjee S, et al. Subintimal dissection/reentry strategies in coronary chronic total occlusion interventions. Circulation Cardiovasc Interv 2012; 5: 729-38.

9. Galassi AR, Grantham JA, Kandzari D, et al. Percutaneous treatment of coronary chronic total occlusion. Part 2: technical approach. Interv Cardiol Rev 2014; 9: 201-7.

10. Rinfret S, Joyal D, Spratt JC, et al. Chronic total occlusion percutaneous coronary intervention case selection and techniques for the antegrade-only operator. Catheter Cardiovasc Interv 2015; 85: 408-15.

11. Maeremans J, Knaapen P, Stuijfzand WJ, et al. Antegrade wire escalation for chronic total occlusions in coronary arteries: simple algorithms as a key to success. J Cardiovasc Med 2016; 17: 680-6.

12. Maeremans J, Walsh $\mathrm{S}$, Knappen $\mathrm{P}$, et al. The Hybrid Algorithm for treating chronic total Occlusion in Europe. J Am Coll Cardiol 2016; 18: 1958-70.

13. Habara M, Tsuchikane E, Muramatsu T, et al. Comparison of percutaneous coronary intervention for chronic total occlusion outcome according to operator experience from the Japanese retrograde summit registry. Catheter Cardiovasc Interv 2016; 87: 1027-35.

14. Sapontis J, Salisbury AC, Yeh RW, et al. Early procedural and health status outcomes after chronic total occlusion angioplasty. J Am Coll Cardiol Cardiovasc Intv 2017; 10: 1523-34.

15. Konstantinidis NV, Werner GS, Deftereos S, et al. Temporal trends in chronic total occlusion interventions in Europe. 17626 procedures from the European Registry of Chronic Total Occlusion. Circulation Cardiovasc Interv 2018: 11: 2-11.

16. Tajti P, Karmpaliotis D, Alaswad K, et al. The hybrid approach to chronic total occlusion percutaneous coronary interventions. Update from the PROGRESS CTO Registry. J Am Coll Cardiol Cardiovasc Interv 2018; 11: 1325-35.

17. Brilakis ES, Grantham JA, Rinfret S, et al. A percutaneous treatment algorithm for crossing coronary chronic total occlusions. J Am Coll Cardiol Cardiovasc Interv 2012; 5: 367-79.

18. Harding S, Wu EB, Lo S, et al. A new algorithm for crossing chronic total occlusions from the Asia Pacific Chronic Total Occlusion Club. J Am Coll Cardiol Cardiovasc Interv 2017; 10: 2135-43.

19. Ge J. Strategic roadmap of percutaneous coronary intervention for chronic total occlusions. Cardiol Plus 2018; 3: 30-7.

20. Galassi AR, Werner GS, Boukhris M, et al. Percutaneous recanalization of chronic total occlusions: 2019 Consensus document from the EuroCTO Club. Eurolntervention 2019; 15: 198-208.

21. Tanaka H, Tsuchikane E, Muramatsu T, et al. A novel algorithm for treating chronic total coronary artery occlusion. J Am Coll Cardiol 2019; 74: 2392-404.

22. Drozd J, Opalińska E, Zapolski T, et al. Percutaneous transluminal coronary angioplasty for chronic total coronary occlusion in patients with stable angina. Relationship between lesion anatomy, procedure technique and efficacy. Kardiol Pol 2005; 62: 332-42.

23. Bryniarski L, Surowiec S, Klima L, et al. Recanalization of coronary chronic total occlusion by retrograde approach: the first experience in Poland. Kardiol Pol 2015; 73: 167-76.

24. Drozd J, Strange J, Wysokińska A, et al. Percutaneous recanalisation of chronically occluded coronary arteries with the Cross-
Boss/Stingray system: first experience (report of three cases). Kardiol Pol 2015; 73: 711-21.

25. Morino $\mathrm{Y}$, Abe M, Morimoto T, et al. Predicting successful guidewire crossing through chronic total occlusion of native coronary lesions within 30 minutes: the J-CTO (Multicenter CTO Registry in Japan) score as a difficulty grading and time assessment tool. J Am Coll Cardiol Cardiovasc Intrv 2011; 4: 213-21.

26. Christopoulos G, Kandzari DE, Yeh RW, et al. Development and validation of a novel scoring system for predicting technical success of chronic total occlusion percutaneous coronary interventions: the PROGRESS CTO (Prospective Global Registry for the Study of Chronic Total Occlusion Intervention) Score. J Am Coll Cardiol Cardiovasc Interv 2016; 11: 1-9.

27. Thygesen K, Alpert JS, Jaffe AS, et al. Third universal definition of myocardial infarction. Circulation 2012; 126: 2020-35.

28. Thygesen K, Alpert JS, Jaffe AS, et al. Fourth universal definition of myocardial infarction guidelines. Eur Heart J 2018; 40: 237-69.

29. Mehran R, Rao SV, Blatt DL, et al. Standardized bleeding definitions for cardiovascular clinical trials: a consensus report from the Bleeding Academic Research Consortium. Circulation 2011; 123: 2736-47.

30. Ellis SG, Ajluni S, Arnold AZ, Increased coronary perforation in the new device era. Incidence, classification, management, and outcome. Circulation 1994; 90: 2725-30.

31. Brilakis ES, Banerjee S, Karmpaliotis D, et al. Procedural outcomes of chronic total occlusion percutaneous coronary interventions: a report from the NCDR (national Cardiovascular Data Registry). J Am Coll Cardiol 2015; 8: 245-53.

32. Vo MN, McCabe JM, Lombardi WL, et al. Adoption of the hybrid СТО approach by a single non-СТО operator: procedural and clinics outcomes. J Invasive Cardiol 2015; 27: 139-44.

33. Pershad A, Eddin M, Girotra S, et al. Validation and incremental value of the hybrid algorithm for CTO PCl. Catheter Cardiovasc Interv 2014; 84: 654-9.

34. Karatasakis A, Danek BA, Karmpaliotis D, et al. Comparison of various scores for predicting success of chronic total occlusion percutaneous coronary intervention. Int J Cardiol 2016; 224: 50-6.

35. Sapontis J, Marso SP, Lombardi WL, et al. How to fix common problems encountered in CTO PCl: the expanded hybrid approach. In: Percutaneous Intervention for Coronary Chronic Total Occlusion: The Hybrid Approach. Rinfret S (ed.). Springer 2015; 141-60. 